\title{
Progress of Perinatal Medicine in Spain
}

\section{José M Carrera*}

Emeritus Member of Dexeus Universitary Institut Barcelona, Secretary General of the International Academy of Perinatal Medicine, Spain

\begin{abstract}
The purpose of this article is to analyze the evolution and progress made in Perinatal Medicine in Spain over the past 40 years. Advances made in the range of technologies used in Perinatal Medicine and their implementation are described: ultrasonography, biophysical and biochemical monitorization (cardiotocography, fetal pH testing, etc.), prenatal diagnosis, amnioscopy, etc. Therapeutic approaches are also discussed: therapeutic uterine activity, fetal intrauterine treatment (medical and surgical), analgo-anesthesia in obstetrics, obstetric surgical technique, conducted when the threat of premature delivery exists, etc.
\end{abstract}

The individuals who made these different advances are cited throughout the text, as are the contributions of Spanish Perinatologists to these areas. For many years Spanish Perinatology was influenced by the so-called "Montevideo School" created by Caldeyro-Barcia. The specialty later embraced all the innovations contributed by European and American investigation groups.

Perinatal results have improved progressively over the years. Spanish levels of maternal and perinatal death are now amongst the lowest in Europe. Not only has the existence of a quality National Health System contributed to these improvements but the dynamism developed in perinatal medicine at some of the country's major hospitals as well.

Keywords: Perinatal medicine; Technology in obstetrics; Medicine in Spain

\section{Introduction}

The concept of Perinatal Medicine was introduced to Spain during the second half of the 1960s in step with changes taking place across Europe and signified a shift from the so-called "art of childbirth" to a more scientific discipline: Perinatal Medicine. It can be said that Spanish obstetricians became aware of the existence of Perinatal Medicine in 1964, when Prof. Caldeyro-Barcia participated in the VIII Portuguese-Spanish Congress of Obstetrics and Gynecology (Sant Feliu de Guíxols, Catalonia) and presented his research on the simultaneous measurement of fetal heart rate (FHR) and uterine dynamics and established the terminology of his findings, especially what he called "dips".

Spanish perinatology was influenced by the so-called "Montevideo school" for many years; the majority of Spanish Department Heads either visited or had fellowships at the Latin American Perinatology Center (CLAP).

A Perinatal Medicine division was founded within the Spanish Society of Obstetrics and Gynecology in 1969 that called annual meetings for all obstetricians interested in the subject. These meetings later turned into Congresses that brought together obstetricians and neonatologists, grouped into the Spanish Society of Neonatology (SEN), every two years. Years later both organizations created an instrumental group, the Spanish Society of Perinatology, for representative purposes only.

New technologies to study the fetus were introduced early in Spain. The first amniocentesis procedure to study fetal erythroblastosis was performed in 1963; however, the first amniocentesis to determine fetal karyotype wasn't performed until 1976. Advocated by Saling, amnioscopy was introduced in 1971, particularly to study fetal maturity during pregnancy and fetal distress during delivery (meconium-stained amniotic fluid). The first obstetric ultrasounds were performed in 1967 by Prof. F. Bonilla from Valencia, and later almost simultaneously in Madrid (P. de la Fuente, C. Chinchilla) and Barcelona (L. Gil-Vernet and J.M. Carerra). Biophysical monitoring of labor by cardiotocography was introduced to Spanish hospitals in 1964 (R. Fuster), first through external measurements and later, in 1967, through internal measurements (J. Esteban Altirriba, Gamissans, P. de la Fuente, J. M. Carrera, etc.). Meanwhile biochemical monitoring, or the Saling Method, was introduced in 1965 in Barcelona (J. Esteban Altirriba, O. Gamissans, J. Massanas, etc.). Although doctors began to timidly use Doppler technology in 1984, the use of Doppler monitoring has now become widespread [1].

\section{Perinatal Results}

Maternal and perinatal mortality rates have improved substantially over the last 30 years. The maternal mortality rate, which from 1970 to 1980 exceeded 20/100.000 live births, has fallen to its current rate of less than $6 / 100.000$ live births. The perinatal mortality rate during the same period exceeded 15/1.000 and has now fallen to less than 3/1.000. The accepted indicator of the quality of obstetric care is perinatal mortality rate, which fluctuates between 3-4/1.000. The morbidity rate has also been considerably reduced. Systematic reviews of maternal and perinatal mortality have been carried out over the last 10 years by J. De Miguel and E. Fabre, respectively.

Currently, $99.5 \%$ of births take place in hospitals. This is the result not only of an improved quality of life in the past few decades (better food, better housing and increased hygiene) but also and especially of an efficient hospital network and an almost model Perinatal Medicine that could be considered one of the best in the world. In fact, Spanish

*Corresponding author: Jose M Carrera, Emeritus Member of Dexeus Universitary Institut Barcelona, Secretary General of the International Academy of Perinatal Medicine, Matres Mundi, Londres 6, p. 808029 Barcelona, Spain, Tel: +34-934190015; Fax: +34-934190015; E-mail: jmcarrera@matres-mundi.org

Received February 16, 2013; Accepted April 18, 2013; Published April 24 2013

Citation: Carrera JM (2013) Progress of Perinatal Medicine in Spain. J Health Med Informat S11: 004. doi:10.4172/2157-7420.S11-004

Copyright: (c) 2013 Carrera JM. This is an open-access article distributed under the terms of the Creative Commons Attribution License, which permits unrestricted use, distribution, and reproduction in any medium, provided the original author and source are credited. 
perinatal results are amongst the best in Europe. Quality care programs based on a monitoring system were introduced in some hospitals from 1992 to 1998 (L. Cabero), designed by a team from the Spanish Society of Gynecology and Obstetrics (SEGO).

The following is a description of the evolution of the main techniques used in Perinatology over the last few decades as well as the advances made by Spanish perinatogist.

\section{Progress in perinatal medicine}

Uterine contractions during labor were first monitored by $\mathrm{R}$. Fuster at the hospital Maternidad Provincial in Barcelona and by J. A. Clavero in Madrid. The first scientific reports on these first studies were presented at a 1962 Symposium on Oxytocin called by Sandoz in Madrid. Later, in 1964, R. Fuster published the "Dynamic Dystocias", considered the first Spanish publication on the subject. A team led by J. Esteban-Altirriba and O. Gamissans performed an in-depth study of fetal pathophysiology and the biophysical and biochemical monitorization procedures at the Hospital de San Pablo in Barcelona from 1965 to 1968 . As a result of this work two books were published that are considered the synthesis of that research effort: "Intrapartum fetal distress" (1967) and "Medical management of labor" (1968). Other teams were later organized with similar aims in different parts of Spain: Dexeus Institute in Barcelona (J. M. Carrera and J. Mallafré), Hospital Clínico in Madrid (J. Botella and J. Clavero), Hospital "La Fe" in Valencia (J. Monleón), Hospital Clínico in Granada (L. Navarrete), Bilbao Hospital (J. Portuondo and J. Blanco,) etc.

All of these teams presented the results of their research at various international forums, and as a result of these contacts different lectures were organized in Spain that were attended by some of the most relevant names in the field at the time: Erich Saling, Arnold Koppler, Alec Turbull, Peter Huntingford, Roberto Caldeyro Barcia, J. J. Poseiro, C. Méndez-Bauer, etc.

New ideas were gradually implemented in the majority of Obstetrics Services at Spanish hospitals. From 1970 to 1975 new technologies became almost routine at two-thirds of the country's hospitals to monitor pregnancies that were considered high-risk. Electronic fetal monitoring (EFM) was even introduced in some private hospitals to monitor all births.

The standard accepted by all Spanish hospitals is that any pathological pattern taken of the FHR should be preceded by acid-base equilibrium study the only procedure that can assess the degree of fetal acidosis. The first studies were carried out from 1964 to 1965 (Hospital de San Pablo in Barcelona) through fetal blood microanalysis (Saling Method).

Attempts were made at clinics to introduce continous $\mathrm{pH}$ measurement through a spiral electrode without success, nor has the "pulse oximetry" become popular in Spain. Some research teams showed more interest in the study of the ST segment of the fetal ECG (Hospital Clínico team in Barcelona, 2000).

Antepartum biophysical monitoring was introduced to Spain between 1975 and 1985 after intrapartum monitoring had been established. In addition to the patient counting Fetal Movements (FM) - a simple, cheap and notably sensitive though non-specific procedure (J. M. Carrera and Colbs., 1977) - the most common procedure in Spain to control antepartum fetus health is the "nostress test" (TNS) which became popular in all hospitals in 1984. Some schools (Instituto Universitario Dexeus) designed and clinically implemented grading systems, like the Dexeus test (1977), as well as specific biophysical profiles (1980-1985). The "contraction stress test" enjoyed certain popularity in the early 1980s (1980-1985), although it has fallen out of use at practically all centers.

Early ultrasound equipment (especially the Siemens Vidoson) arrived in Spain around 1967. The pioneers of the technique were Prof. F. Bonilla of Valencia, who had been trained along with Hinselman, and Professors Pedro de la Fuentes and Chinchilla from Madrid. The procedure was introduced almost simultaneously in a number of Barcelona hospitals in 1970: the Hospital Clínico (J. A. Vanrell and J. Fuster), Hospital de San Pablo (M. de Sostoa), the Dexeus University Institute (J. M. Carrera, M. Alegre, C. Mortera) and at the Hospital de la Seguridad Social (L. Gil Vernet). Somewhat later the procedure was introduced in Galicia (R. Cajide), Andalusia (R. Comino, M. Mas Masats, Abshera and Bedoya), Tenerife (J. Parache), etc. Virtually all current sonographers were either students or employees of this first generation of Spanish sonographers. The first books on the subject by F. Bonilla, J. Parache, P. de la Fuente and J. M. Carrera were published from 1972 to 1980 [2].

There was a degree of specialization from the start: the first studies on fetal biometry were conducted by F. Bonilla and P. de la Fuente; the first reported diagnosis of malformations were done by F. Bonilla, J. Parache and C. Chinchilla and the first studies on intrauterine growth restriction (IUGR) were performed by the Dexeus University Institute (Carrera and Colbs.).

Early ultrasonography classes were given in Valencia by Prof. F. Bonilla in 1968 and 1969 and the first international symposiums were organized by L. Gil Vernet in Barcelona (1974) and R. Cajide in Santiago de Compostela (1974) with the participation of a number of leading figures like Robinson, Levi, etc. In succeeding years (1978 on) various International Symposiums were held at the Dexeus Institute, attended by international masters like Arduini, Bovicelli, Campbell,Catizone, Chervenak, D'Addario, Eik-Ness, Elejalde, Hansmann, Hollander, Ianniruberto, Jauniaux, Joupila, Kurjak, Levi, Maeda, Merz, Nicolaides, Rizzo, Rodek, Romero, Timor-Tritsh, Wladimiroff and Zacuti.

Obstetric-gynecology ultrasounds were already in use at practically all Spanish Obstetrics and Perinatal Medicine Services between 1975 and 1976. In 1985 the SEGO and its Ultrasound department began to recommend at least three ultrasounds over the course of pregnancy (once per trimester) for all pregnant women, regardless of whether the pregnancy is high or low-risk. This standard is currently met for $95 \%$ of all pregnancies.

The current tendency in Spain is to use ultrasounds to define specific groups of risk which should be monitored and treated differently. Ultrasound Schools from the Dexeus University Institute (C. Comas, M. Torrents, etc.), Vall d'Hebrón (E. Carreras, Muñoz, etc.) and Hospital Clínico (J. M. Martínez, Figueras, etc.) in Barcelona and the Hospital Clínico in Valencia (Bonilla) have contributed information on the subject.

Early invasive techniques under ultrasound guidance were performed by Chinchilla (1975), Race (1977) and Fortuny (1978). The TM modality was used regularly in Madrid by P. de la Fuente, Yueste and Villar (1979-1980). The Ultrasound Department of the Spanish Society of Obstetrics and Gynecology was founded in 1977. The internationalization of the Spanish ultrasound occurred in 1981.

From 1983 to 1986 the 2-D fetal echocardiography (Mortera, P. de la Fuente, Olaizola, etc.), the Doppler velocimetry (Diaz Recasens, 
Mortera, Galindo, and Olaizola) and vaginal probe (F. Bonilla, Pérez Gil, P. de la Fuente, J. Bajo Arenas, etc.) were introduced.

The study of fetal behaviour by means of 4-D ultrasonography provides the most useful indicators of brain function. Following Kurjak's pioneering studies (2004) a number of Spanish authors made important contributions to the field (Azumendi, Carrera, etc.).

Doppler technology used specifically to study fetal cardiac anatomy (fetal echocardiography) was first practiced in Spain in 1983 by C. Mortera at the Hospital de San Juan de Dios and the Dexeus University Institute in Barcelona. P. de la Fuente, Yuste and Villar had used the TM method in 1979 and 1980 with the same objective. But the earliest fetal hemodynamics studies with a pulsating Doppler to study the fetal condition were performed at the Dexeus University Institute (C. Mortera, M. Alegre, and J. M. Carrera) in 1983. However, the pioneer in these studies was J. Diaz Recasens, the first Spanish doctor who worked on "Doppler in the Umbilical Artery" with Campbell [3]. Shortly after, the same studies were performed at the Hospital Clínico in Barcelona and the Hospital La Paz in Madrid (P. de la Fuente, Olaizola, Galindo, etc.). Doppler in color was implemented in 1989 and greatly facilitated fetal hemodynamic studies.

In 1989 the European Association of Prenatal Medicine, in collaboration with the Spanish Association of Prenatal Diagnosis, organized the "European Meeting and Symposium on Doppler Fluxometry in Perinatal Medicine" in Barcelona, chaired by Prof. S. Campbell and Dr. José M. Carrera [3]. All European doctors involved with the use of Doppler in Obstetrics attended the meeting, including: E. Reinold, P. Jouppila, J. M. Thoulon, E. Saliba, V. Colloridi, G. Pardi, A. Kurjak, S. H. Eik-Nes, P. de la Fuente, C. Mortera, R. Huch, N. R. Lundström, K. Marsal, K. Nicolaides, M. Anthony, J. Diaz-Recasens, G. Mandruzzato, J de Haan, L. Allan, P. Arbeille, D. Arduini, D. Evans, E. Ferrazi, G. Sharland, N. O. Sjöberg, J. Van Eych, etc. The impulse behind the meeting and the creation of a European Committee was the rapid spread of a sophisticated and expensive technique which had yet to prove its scientific value due to a lack of adequate control studies in most European hospitals. However, its role in perinatological decision making had increased. The findings were published in a book entitled "Regulation for the use of Doppler Technology in Perinatal Medicine" that was distributed to all European Perinatal Services and provided better scientific support of the Doppler technique. The book included texts in three languages (English, French and Spanish). This "Barcelona Consensus" was later published in Italian and Spanish and has undoubtedly provided the basis for all subsequent Doppler findings.

Llurba and Colb. made an important contribution to the role of Doppler in the uterine arteries to predict preeclampsia and IUGR in 2004. Remarkable advances were also made along these lines by a number of Spanish sonographers like Carrera (1990), Puerto (1994) and Borrell (1998).

Once ultrasounds became an established practice in Spain the first prenatal diagnostic programs were conducted in departments or units designed specifically to that end. The pioneering programs were implemented at the Hospital Clínico in Madrid (C. Chinchilla, 1976), as well as in Barcelona, first at the Hospital Clínico (A. Fortuny, 1978) and shortly after at the Dexeus University Institute (J. M. Carrera, J. Mallafré and M. Alegre, 1979).

As mentioned above, the first amniocentesis to determine the fetal karyotype was performed in Madrid (C. Chinchilla), yet the first chorion biopsies and funiculocentesis (cordocentesis) were performed at Barcelona's Hospital de San Pablo in 1986 by M. de Sostoa and J.
Parra after the two worked in London under C. H. Rodeck. Shortly thereafter (1987) these techniques were also introduced at the Dexeus Institute (J. M. Carrera, C. Salvador and J. Mallafré) and Hospital Clínico (A. Fortuny) in Barcelona, thanks once again to the learning of these techniques through Bovicelli (Bologna) and Rodeck (London), respectively. Around this same time P. de la Fuente (Hospital La Paz in Madrid) introduced cordocentesis after studying with I. Dumez (Paris).

Important milestones that marked the development of Prenatal Diagnosis in Spain were the foundation of the "Spanish Association of Prenatal Diagnostic" (AEDP) in Barcelona in 1998 and the publication of the "Prenatal Diagnostic Progress" journal in 1989. Both definitively boosted prenatal Diagnosis in Spain to reach the level of the most advanced countries in the subject. The AEDP organized the first national congress on prenatal Diagnosis, which continues today through biannual congresses.

Detection of fetal morphological or structural defects by ultrasound was performed in Spanish hospitals from 1973-1974 and a protocol was established in 1980. From then on major hospitals established malformation "screening" programs. The prenatal diagnosis is a now a current practice (99.2\%) in Spain. J. M. Carrera, using his experience at the Dexeus University Institute, published a book in 1987 ("Prenatal Diagnosis") that was based on an entire generation of sonographers.

The so-called "sonographic markers of chromosomal abnormalities" began to be used at two Barcelona services: at the Dexeus University Institute (Alegre, Carrera, Torrents, etc.) and Hospital Clínico (Borrell, Martinez, Comas, etc.). In 1994 the first machines with 3-D were acquired (Bonilla) and 4-D scans were introduced to major hospitals in 2004; the STIC (Spatio-Temporal-Image-Correlation) technique was gradually introduced as well as the computerized analysis of volume (VOCAL or Virtual Organ Computer Aided Analysis).

The European Society of Perinatal Medicine founded the "European Study Group on Prenatal Diagnosis" in, 1991. Presidency was given to Carrera, who called an International Symposium in Barcelona that was attended by some of the world's top specialists of the time: $\mathrm{S}$. Levi, A. Kurjak, A. Boué, A. Antsaklis, B. Brambati, M. Hansmann, Z. Papp, H. Galjaard, K. Nicolaides, F. Daffos, G. C. Di Renzo, G.Simoni, S. Campbell, T. K. A. B. Eskes, J. Wladimiroff, Ch. de Andreis, W. Holzgreve, P. Mastroiacovo, V. Mirlesse, C. Mortera, A. Fortuny, J. Diaz-Recasens, etc. The symposium resulted in the publication of the "Recommendations and Protocols for Prenatal Diagnosis" by J. M. Carrera and G. C. Di Renzo. The publication, printed simultaneously in English, French and Spanish, was instrumental in bringing order to the correct application of still new prenatal diagnostic techniques. Other editions in these three languages were later published with updated content and included numerous appendices: a list of worldwide teratogen information services, guidelines for ultrasound screening for congenital anomalies, AIUM guidelines for antepartum obstetric examination, recommendations on the use of ultrasound and Doppler technology in clinical obstetrics and gynecology and inborn errors of metabolism and the level at which the prenatal diagnosis can be done.

An important fact that influenced the rapid advancement of Prenatal Diagnosis in Spain was the foundation of the Ian Donald School of Ultrasonography in Dubrovnik in 1992, directed by Prof. Asim Kurjak, which now has 100 branches all over the world. In Spain, the school was originally directed by F. Gónzalez-Gómez and later by J. M. Carrera and C. Comas. The School holds successful biannual courses.

Another notable event was the creation of the "Ibero-American Prenatal Diagnostic Society" in Acapulco (Mexico) in 1995, where the 
fist Ibero-American Congress on Prenatal Diagnosis was held. This Society holds conferences every two years and is currently headed by Quintero.

In 1999 all of this interest in birth defects led to supplement the diet of pregnant women first with folate and then with iodine (2004). In this sense the Zaragoza group made important contributions [4]. It could be said that consideration of the embryo as a patient and therefore the introduction of the Embryonic Medicine has been the consequence of four kinds of events:

1. The acquisition, as a result of assisted reproduction techniques, of new and unexpected knowledge about the implantation of the conceptus of uterine receptivity and immune tolerance at the fetomaternal interface and its abnormal and pathological aspects.

2. Improved understanding of early embryo development and the placenta.

3. The progressive introduction of various types of embryo monitoring and diagnostic techniques.

4. The application of ultrasonography and its variants, during the first trimester of pregnancy.

The Dexeus University Institute as well as the Instituto Valenciano de Infertilidad has made important contributions to this field.

In 1990, the maternal immune response to certain infectious agents such as rubella, toxoplasmosis, cytomegalovirus, herpes simplex virus, Hepatitis B, Hepatitis C, parvovirus B-19 and Human Immunodeficiency Virus (HIV) were selectively studied across Spain. This fact explains the development of the immnulogical screening techniques. Soon techniques such as the activity reaction and the study of fetal blood using cordocentesis, the presence of the infectious agent in the placenta (chorion biopsy) or amniotic fluid and PCR analysis of the DNA sequences of the causal agent were used. A number of Spanish perinatologists like Coll (HIV), (toxoplasmosis), Xercavins (herpes virus), etc. distinguished themselves in this field [4].

In 1998 the Spanish Societies of Obstetrics and Neonatology published a consensus document on the prevention of neonatal disease through beta-hemolytic Group B Streptococcus (GBS) following the strategy of the United State's Center for Disease Control, which recommends the universal screening of all pregnant women and the use of intrapartum antibiotics for all colonized pregnant women.

\section{Progress in Perinatal Therapy}

The uterine activity therapy is one of the most important developments in perinatal medicine. The intravenous use of pituitrin to pharmacologically induce labor was first performed by Fuster at the Maternidad Provinical in Barcelona in 1954. The first publication on the use of synthetic oxytocin was written by J. Esteban-Altirriba and Salamero-Raymundo in 1958 at the Instituto Municipal de Maternología in Barcelona. Around this same period Orgengo Diaz del Castillo used the procedure for the first time in Madrid.

The use of oxytocin to induce labor became the practice in many Spanish hospitals thanks to the introduction of the Cardiff method. The first induction was conducted at Barcelona's Hospital Clínico after the method's creator Prof. Alec Turnbull visited Barcelona. However, the Theobald method of intravenous drip administration with or without an infusion pump eventually won out.

The early works on uterolytic beta-adrenergic drugs were done by the Esteban-Altirriba team at the Hospital de San Pablo in Barcelona. The first intrauterine measurement of uterine dynamics inhibited by betamimetic (isoxsuprine) was published in "Intrapartum Fetal Distress" (1967). The use of prostaglandin synthesis inhibitors was studied for the first time in Spain by a team led by O. Gamissans at Barcelona’s Hospital Clínico. He published the team's entire experience with the subject in 1968. The same team published groundbreaking work on the treatment of intrapartum fetal acidosis through betamimetics from 1967 to 1980 Some of these works were presented as keynote speeches at the World Congress in Moscow (1973). Cabero later contributed his experience to the subject (1981-1988).

In the fight against prematurity apart from the increase in the overall survival rate of premature babies through the use of incubators, which were introduced to Spain shortly before the Civil War, the first major step towards improving the diagnosis and prognosis of premature births was the ability to specify the fetus' lung maturation by determining the lecithin-sphingomyelin ratio (L/S ratio) in amniotic fluid obtained through amniocentesis. Another procedure, called the Clements test, was introduced to Spain by the Hospital de San Pablo School (EstebanAltirriba and Cabero). The determination of phosphatidylglycerol and phosphatidylinositol was later introduced.

In recent years the preventive strategies to avoid prematurity have improved the cervical ultrasound evaluation of the cervical length and "funneling " (Dexeus Institute in Barcelona), the vaginal detection of fibronectin and other biochemical markers that are currently in widespread use in hospitals across Spain.

Finally, new trends in tocolysis, specifically the blockage of oxytocin receptor drugs, steroids administration, as well as the transfer of the mother to adequate centers have improved the perinatal mortality rate for premature babies (Cabero).

About fetal therapy we can say that only a few centers in Spain, primarily in Barcelona (E. Gratacós, E. Carreras, etc.) and Madrid (Hospital La Paz), currently perform intrauterine fetal therapy procedures. Until recently the procedures were limited to those that could be performed with ultrasound guidance (intravascular fetal transfusion, drainage techniques, etc.). However, these fetal endoscopic and/or open surgeries have been performed in selected cases at these centers.

In 1995 fetoscopies began to be used in Spain to perform laser coagulation of vascular anastomoses in Twin-to-Twin Transfusion Syndrome (TTTS), cord occlusion in monochorionic twin gestation (acardiac fetus and reversed-twin arterial perfusion), the temporary tracheal occlusion for congenital diaphragmatic hernia (1996) or the successful coagulation of the feeder veins of a sacrococcygeal teratoma. Open fetal surgery techniques were developed at almost the same time, including the treatment of congenital cystic adenomatous malformations of the lung, open fetal surgery for sacrococcygeal teratoma resection and myelomeningocele repair. Many of these techniques, performed particularly by Gratacós in Barcelona, have been developed by a group of European specialists including Deprest, Devlieger, Van Schoubroeck and Gratacós (2000) (Eurofetus registry). This same group has also made significant contributions to the study of the pathophysiology of preeclampsia (Gratacós, Llurba, Cabero, etc., 2004).

The earliest intrauterine transfusion in Spain was performed by Sas de la Encina and Oppenheimer at the Hospital General de la Seguridad Social in Barcelona in 1966. The second procedure was performed a few months later in Barcelona by J. M. Dexeus, Doménech and 
Oppenhaimer. At that time the procedure was done with radiological monitoring, as ultrasounds were not yet available.

In 1970, the "Hispano-Lusitanian Obstetrics and Gynecology Congress" was held in Palma, Mallorca; one of the keynote speeches was entitled "The Rh problem in Obstetrics." During the talk the technique was discussed and Muxi, who headed the Rh team at the Hospital de la Seguridad Social in Barcelona, presented a statistic of 46 intraperitoneal transfusions.

The first regulated intravascular transfusion was performed with ultrasound guidance at the Hospital de San Pablo (M. de Sostoa and J. Parra) in 1986. The team presented the results of the first techniques at the XII World Gynecology Congress in Rio de Janiero (1988).

Both techniques were later abandoned as ultrasound findings (cerebral arteries, etc.) made them virtually unnecessary.

\section{Progress in Labor}

In the field of the obstetric surgery over the last fifties years the use of forceps, vaginal extractor par excellence, was implemented in Spain along with two new procedures: vacuum extraction and obstetrical spatulas. These procedures replaced pelviotomy, symphysiotomy, fetotomy, vaginal cesarean section and other remarkably aggressive techniques.

Fernandez-Ruiz introduced the vacuum extractor to Spain in 1952. But the first center that quickly adopted the procedure as almost routine standard obstetric treatment was the Hospital Maternidad Provincial in Barcelona (J. M. Dexeus, 1954). The procedure spread rapidly throughout the country, completely replacing the use of forceps at some centers. Barcelona's Maternidad Provincial spread the use of Kyelland forceps and J. M. Dexeus contributed important modifications to the instrument to make it easier to use (1956).

The earliest use of Thierry spatulas was in 1965 at the Obstetrical Service of the Hospital Clínico of Barcelona, directed by Gil-Vernet, who published a first series in 1966 . The spatulas were used almost immediately (1967) at the Dexeus Clinic and later at the Hospital de San Pablo and the Maternidad Provincial in Barcelona (1967-1968), then spreading throughout Spain. The external version in breech presentation technique using ultrasound monitoring and betamimetic treatment (Cararach) was reintroduced in 1999.

Abdominal cesareans accounted for between 1-2\% of all births at major Hospitals during the middle of the last century. At that time it was believed that under no circumstances should c-sections exceed 5\%; if that was to happen, the maternity ward had to be closed (which took effect in France for a time). However, that percentage was exceeded in many hospitals in 1960, quickly reaching $20 \%$ three decades later. Today, many hospitals have percentages that reach $30 \%$ or more. This increase is due in part to the changes that took place in reproductive customs (later maternity, tendency to have just one child, an increase in multiple gestations and premature births, "a la carte" childbirth, etc.) but also to "defensive" medicine, which prevents vaginal deliveries for women with previous c-section or breech deliveries. On the other hand, obviously, the possibility of detecting fetal distress with modern methods (CTG, Doppler, etc.) much earlier than with traditional procedures requires fetal extraction through c-sections. Today the standard cesarean section in all the country's maternity services is a cesarean section with Pfannesntiel incision.

Analgo-anesthesia obstetrics wasn't introduced to Spain until the late 1950s. Only cesarean section and, in some centers, operative vaginal deliveries made use of general anesthesia. The anesthetic gas was usually ether. Fluothane (alotane) began to be used just a few years later (1965). Small doses of Demerol and the breathing of trilene were used as analgesics, especially at private clinics. But things changed in 1960. Pontonnier in France popularized the "Toulouse Method", which consisted of the intravenous administration of Pentothal (pentobarbital) on demand, and 4-5 years later it was administered by drip (Bedoya), considerably increasing the technique's acceptance (the anesthesia can be prolonged for hours).

However, public medicine kept inexorably following the biblical sentence of "childbirth is painful", with pain only relieved by the course of the so-called "Psychoprophylactic Method". Despite this tendency, a notable proclivity for local anesthesia was reached in this environment, particularly pudendal block and paracervical anesthesia. Epidural anesthesia was introduced in 1968 (substituting the Caudal that had fallen into disuse due to its problems) and became widespread in both private and public clinics in 1980. For many years the pioneers in childbirth analgo-anesthesia had to face often verbally violent defenders of the biblical curse.

Pain relief during delivery is the standard across Spain with the current use of increasingly reliable drugs and techniques. However, the birth of some increasingly influential movements should be noted; these movements cry for "natural births" without medical or surgical interference.

\section{Progress In Neonatology}

While the term "Neonatology" began to be used in Spain in 1960, early "Intensive Care Nurseries (ICN)" were established in the 1950s in step with progress in the care and treatment of premature babies. At this time the principal interventions were resuscitation, thermoregulation, supporting care for respiratory distress, etc. In 1956 the majority of Spanish maternity wards were using the Apgar score to evaluate newborns and phototherapy was also introduced around this time. By the 1960s electronic monitors came into use and blood gases began to be measured. Feedings were aided by nasogastric tubes and increased laboratory monitoring became possible. The use of umbilical catheters and arterial pressure transducers were routine by the 1960s and 1970 s, and respiratory therapy for hyaline membrane disease began to succeed. Nutritional support for sick infants was aided by transpyloric feeding tubes and finally by complete intravenous alimentation. All of these techniques were initially used in Madrid (Quero) and in Barcelona (Ballabriga, Carbonell) and were progressively adopted by other pediatric hospitals (Valencia, Bilbao, etc.).

Computer tomography and ultrasonography were introduced to hospitals in 1980 as well as transcutaneous electrodes for measurement of oxygen and carbon dioxide. ICNs in major maternal-infant hospitals began to incorporate new procedures in 1990: magnetic resonance, positron, tomography and magnetic resonance spectography, etc. The Spanish Neonatology Society (SEN) has published guidelines on Neonatal Cardiopulmonary Resuscitation (NCR) which has led to all neonatologists and obstetricians mastering the different skills (2004). Spanish neonatology is currently amongst the most advanced in Europe, with an above-average number of neonatologists.

\section{Progress in Organisation}

The Spanish National Health System is very good. "Obligatory health insurance" or SOE was implemented in Spain in 1942 to cover health care for all workers. At first, maternal care was available in hospitals only for complicated births. The delivery took place at home 
in all other cases and mothers were assisted by midwives. However, in the 1950s the possibility of attending women whose homes did not meet appropriate conditions for delivery in a hospital was considered. This created the rhetorical figure of the "social dystocia" and with it the increase in hospital births by the end of the 1960s. A large number of Obligatory Insurance hospitals were created to handle this increase, especially in major cities. The insurance was later restructured under the name of Social Security and the hospitals finally established a hierarchy which increased effectiveness considerably. Most delivery (99.4\%) takes place in Hospital.

The health system currently insures all pregnant women for their prenatal monitoring (including a prenatal diagnosis) and deliveries take place in perfectly organized and equipped hospitals where the patient can decide, for example, if she wants an epidural.

The hospitals and the services they provide are classified into levels. Nationally and internationally renowned maternity hospitals are, for example, the 12 de Octubre, La Paz, Rubber International, Santa Cristina, etc. hospitals in Madrid, and the maternity wards at the Hospital Clínico Valle d'Hebrón, Instituto Universitario Dexeus in Barcelona as well as the Hospital La Fé and the School of Medicine in Valencia.

The Perinatal Medical Education was traditionally taught in some hospital departments that had not only the material and human resources required but also the experts or leaders in the field. Wellknown medical schools were the Botella Schools in Madrid, the Dexeus, Fargas or Conill school in Barcelona, Bonilla in Valencia, Bedoya in Seville and Novo in Santiago de Compostela. The training of specialists was done at these departments and schools for many years. The Professional Specialists Schools were founded in 1955 in accordance with the law on "Teaching, degree and exercise of medical specialists" and failed because they were unable to provide adequate practical training to all students.

The North American model of "Residency" was adopted in Spain in 1975 as well as the MIR exam for Resident Physicians, which organized the field and ensured superb training for specialists both in Obstetrics and Pediatrics. Between $10-15 \%$ of all Resident Physicians who pass their exams each year later choose to subspecialize in Perinatal Medicine. These Perinatologic experts hold clinical and research posts in public and private centers; highly qualified in their specialty, these doctors are key figures in their field. A National Commission for the specialty has been established and develops training programs, decides which centers can be used for training and monitors the entire process.

About the Scientific Societies the Spanish Gynecology Society was founded in 1874 and has undergone several name changes over the years; the current name is the "Spanish Society of Gynecology and Obstetrics" (SEGO). Several specializations exist within the society, including Perinatal Medicine (SEMEPE) and Obstetrics-Gynecology Ultrasounds (SESEGO). In addition, each of Spain's autonomous communities has a regional Obstetrics Society.

The pediatric field is represented by the "Spanish Association of Pediatric" (AEP) and the "Spanish Society of Neonatology" (SEN). Other specialized societies in addition to the aforementioned groups have also been founded in recent decades including the Spanish Association of Prenatal Diagnosis and the Spanish Society of Perinatal Medicine.

Spain also forms part of a number of multi-national Perinatal Medicine associations like the "European Association of Perinatal
Medicine", the "World Association of Perinatal Medicine" and the "International Academy of Perinatal Medicine". Hispano-Portuguese as well as Mediterranean-Latino obstetrics and gynecology congresses are also occasionally held. All of these societies have websites that provide clinical guidelines, contests, medical-legal documents, photo galleries, bioethical criteria, etc.

Spanish Perinatal Medicine specialists have depended on different protocols and guidelines that have standardized good practice and unified medical criteria at all hospitals since 1980. These guidelines have been published by the corresponding scientific societies or by renowned Maternal Centers (Dexeus University Institute, Hospital Universitario Vall d'Hebrón Obstetrics Department, etc.). The scientific base of these guidelines is founded as much as possible on "evidencebased medicine" (EBM). The need for these documents has increased with the massive influx of new technologies.

The "Spanish Society of Obstetrics and Gynecology" (SEGO) as well as the "Spanish Pediatrics Association" (APE) have also produced a number of consensus documents issued by the corresponding teams. Systematic high-quality revisions have also been published in recent years following the "Cochrane Database" criteria. The subjects are diverse: prematurity, twins, maternal mortality rate, etc. (Fabre, Cabero, Bonfill, etc.).

To conclude, the efforts of some organizations like the Instituto Borja de Bioética must be mentioned; from 1975 to today the organization has contributed knowledge on bioethics in perinatal medicine through dialogue and deliberation on case studies with conflicting values. These initiatives have led to the creation of "Bioethics Committees" in large hospitals.

\section{Conclusions}

If we analyse the progress achieved in Perinatal Medicine in Spain these last 40 years we realise that during this period of time there has been a continuous improvement of maternal and neonatal care which has situated Spain as one of the European countries with best results in this field.

These are the most important conclusions of this analysis which is based on absolute reliable statistics:

1. Maternal mortality rate ( $<6$ per 100.000 live births) and perinatal mortality rate ( $<3$ per 1000 live births) are amongst the lowest in the world.

2. Most deliveries (99.4\%) take place in well-equipped maternity hospitals with the support of skilled obstetricians or midwives.

3. The public hospital network that covers the whole country is one of the best in Europe.

4. The techniques to control the fetus during pregnancy (biophysical techniques, ultrasonography, etc.) have been applied for a very long time and have an excellent standard of quality at this moment.

5. The prenatal diagnosis of congenital defects by means of biochemical and ultrasonographic techniques is now a current practice (99.2\%) reaching levels above the European average.

6. Prenatal care and control is universal and free so that the percentage of women that do not follow the established protocol is less than $2 \%$.

7. The intrapartum control using biochemical and biophysical 
assessment methods is a usual practice in Spanish public and private maternity hospitals.

8. Neonatology in Spain has reached high standards of quality. There is almost no maternity hospital without a Neonatology Service. The number of neonatologists is probably one of the highest in Europe.

9. Some Spanish perinatologists have been pioneers in the intrauterine fetal treatment, medical and surgical.

10. The Spanish National Health System, even with the budget restrictions due to the current economic crisis, garantees a correct medical assistance during pregnancy and delivery to all women, illegal immigrants included.

11. Several Scientific Societies (Obstetrics, Pediatrics, Perinatology and Neonatology) provide scientific updating for the Spanish perinatologists and draw up protocols that guarantee a correct perinatal assistance.

\section{References}

1. Lope V, Pérez-Gómez B, Sánchez-Contador C, Santamariña MC, Moreo P, et al. (2012) Obstetric history and mammographic density: a population-based cross-sectional study in Spain (DDM-Spain). Breast Cancer Res Treat 132: 1137-1146.

2. Carrera JM (1980) Monitorización fetal anteparto. Salvat. Edit. Barcelona.

3. Campbell S, Carrera JM (1989) Regulation for the use of Doppler Technology in Perinatal Medicine. European Committee on Doppler Technology in Perinatal Medicine, Instituto Dexeus, UK

4. Usandizaga JA, González G (2007) History of Spanish Obstetrics and Gynaecology. Habe Edit Madrid, Spain. 